\title{
Crafting a Rich and Personal Blending Learning Environment An Institutional Case Study from a STEM perspective
}

\author{
Su White ${ }^{1}$, Hugh Davis ${ }^{1}$, Kate Dickens ${ }^{2}$ and Sarah Fielding ${ }^{2}$ \\ ${ }^{1}$ Web and Internet Science, University of Southampton, Highfield, Southampton, UK \\ ${ }^{2}$ Centre for Innovation in Technologies and Education, University of Southampton, Highfield, Southampton, UK
}

$\{$ saw,hcd\}@ecs.soton.ac.uk, \{kate.dickens,s.fielding\}@soton.ac.uk

\begin{abstract}
Keywords: Institutional Initiative, Design Patterns, Disciplinary Differences, TEL, E-Learning, PLEs, Co-Design, Participatory Design.

Abstract: Institutional pressures to make optimal use of lecture halls and classrooms can be powerful motivators to identify resources to develop technology enhanced learning approaches to traditional curricula. From the academic's perspective, engaging students in active learning and reducing the academic workload are important and complementary drivers.
\end{abstract}

This paper presents a case study of a curriculum development exercise undertaken in a STEM subject area at a research-intensive UK university. A multi-skilled team of academics and learning designers have worked collaboratively to build this module which will be realised as a mix of online and face to face activities. Since the module addresses professional issues, a strong emphasis is being placed on establishing authentic learning activities and realistic use of prominent social tools.

The learning designers are working for a cross-institutional initiative to support educational innovations; therefore it is important to carefully document the development process and to identify reusable design patterns which can be easily explained to other academics.

\section{INTRODUCTION}

This case study provides a reflective account of the processes needed by a multi-skilled team to develop a blended learning module. Following an institutional wide initiative to establish a centre for innovation in technologies and education (CITE), a number of target curriculum areas have been identified as candidates to establish or demonstrate educational design patterns (Goodyear, 2005; Goodyear and Retalis 2010). The intention is to use design patterns to explain workable and pedagogically clear responses to recurrent educational problems. The rationale which underlies these responses will be exposed in a clear and systematic manner enabling them to be more widely understood and then reused by colleagues across the wider university.

The selection of target areas has sought to take into account disciplinary differences (Biglan, 1973) and the consequent variability in prefered practice and effective strategies across different cognate disciplines (Jones, Zenios and Griffiths 2004; White and Liccardi 2006). The changes enacted, and specific modules identified as exemplars typically incorporate responses to local drivers for change which can be widely recognised. These encompass imperatives beneficial to learners, the institutuion and to teaching academics:

- Increase the active participation of students to take more responsibility for their own learning

- Introduce situated technologies which develop students' mastery of digital literacies; 
- Address needs of students learning on and off campus simultaneously;

- Reduce demand on large lecture theatres;

- Reduce marking load for academics.

The advantage of addressing such local drivers is that success in these areas is also valued by the wider university, and, in a time of financial stringency effectively promises to improve the effectiveness and efficiency of the teaching processes. Notwithstanding these top level priorities, no pattern would be acceptable unless it incorporated sound pedagogical principles.

This case concerns the design of a 'professional issues' module which equates with 150 total teaching + study hours taken by a mixed cohort of Software Engineering, Computer Science and Information Technology students. Typical cohort size is 150 students, with the module being taught during one twelve week semester. The module will be led by two experienced academics who have designed and taught the two 100 hour predecessor modules on which the revised module is based.

Some of the content and philosophy of the existing modules are being incorporated into the new design. Both academics have a had extensive prior involvement in curriculum design and establishing teaching innovations plus a practical and research experience in technology enhanced learning.

The academics are keen to preserve, yet transpose, the activities which they have observed to be effective during the predecessor modules. They are also seeking to alleviate pressure points generated by trying to manually organise the workflow generated by activities which have evolved and now incorporate a high degree of complexity.

The academic expertise of the multi-disciplinary design and development team is a particular strength. CITE is co-located with the Web and Internet Science research lab in Electronics and Computer Science. It is led by a senior Computer Science academic and the design team include experienced software engineers with significant track record working on participative design projects implementing technology enhanced learning.

Similarly, all of the learning designers have extensive practical experience. They are already skilled at specifying, designing and deploying a broad range of educational resources and online learning activities. In addition they understand the potential benefit of participatory design and cocreation which enables them to gain insights to academics' educational motivations. For this reason, they particularly value the collaborative nature of this work.
The remainder of this paper provides a structured account of the technical and pedagogic balance which has been established during this design activity. It addresses the four themes of :

- Information technologies supporting learning;

- Learning and teaching methodologies and assessment;

- Social context and learning environments;

- Technology enhanced learning in STEM disciplines.

It provides an account of the working methods employed and presents an interim reflective evaluation of the activity. An outline of future work is proposed.

\section{BACKGROUND}

The two professional issues modules which this design is seeking to replace are both taught in a predominantly face-to-face manner. They aim to develop soft skills using authentic activities to create opportunities for situated learning. Students who successfully complete the modules will have demonstrated broadly:

- An understanding of the legal ethical and professional issues relevant to an IT specialist during their working life;

- An understanding of their personal learning preferences;

- An ability to research and communicate technical information;

- Incorporating in their routine learning practices an ability to reflect objectively and critically evaluate their own and other's work.

All the degrees to which this module contributes are accredited by the British Computer Society, which to some extent determines and constrains the content which is addressed and the assessment methods used.

\subsection{Teaching and Assessment}

The teaching methods employed in the predecessor classes are a mix of large lecture classes and small group sessions. The lectures incorporate individual and group student activities and are complemented by a number of assessments including, individually:

- Preparing a CV;

- Researching and writing a technical report;

- Preparing an annotated bibliography;

- Demonstrating basic legal understanding via an online test 
- Undertaking an open book exam evaluating professional issues in a seen case study.

As a group

- Researching and making a group presentation on a technical topic;

- Building and creating an information resource;

- Creating and presenting a group poster.

\subsection{Key Challenges}

One obvious challenge is how to consolidate the assessments for the new module. This requires careful consideration. The new module has a nominal education study and contact time which is $25 \%$ less than the two established modules.

Clearly cuts and changes have to be made. The academics have a clear sense that students' behaviours, learning and perceptions of priorities are shaped by their experience of assessment. As Boud argues: assessment shapes learning, in addition, there is a clear need in this case to craft assessments which develop "the kinds of highly contextualised learning faced in life and work" (Boud and Falchikov, 2005).

This argument is consonant with Bigg's emphasis on the value and importance of ensuring that the assessments are constructively aligned with the curriculum. Furthermore it may well be possible to gain mutual benefit for students and academics. Although it is front heavy to undertake the process of structuring and framing peer reflection and evaluation to be embedded in the teaching, this process may well reward academics with long term time saving, whilst the student experience is also enhanced.

\subsubsection{Disciplinary differences}

There is a particular challenge in teaching professional issues to students from the computing disciplines. Such students typically have specialised in technical subject early in their academic career; as is typical in the UK education system. Many students acknowledge they purposefully selected study options which avoid any volume of writing.

In disciplinary terms, their preferences, and the bulk of the topics, knowledge organisation and study practices are those of Biglan's Hard Soft fields of study, with some overlap into Hard Pure activities (Biglan, 1973a). By contrast the topics of professional issues are more closely identified with the Soft Applied fields of study. The specific challenge is identifying and using teaching methods and associated study activities which are compelling and aligned with the soft applied (Neumann, Parry and Beecher, 2002).

\subsubsection{Sustaining Motivation}

In order to address the challenge consequent of disciplinary differences in the existing predecessor modules, much care has been taken in the way in which the motivation for the study area is explained to the students. The modules are presented as providing an opportunity which will enable students which an acknowledged preference for the technical focus of their chosen degrees to:

- Demonstrate a broader understanding of the professional legal and ethical issues which complements their technical expertise;

- Individually tailor a high degree of matching knowledge and understanding for topics which relate to their personal technical preferences and specialisms

- Acquire expertise in knowledge and processes which will offer them opportunities for success in the job market and during future careers.

Activities and assessments are designed to meet the ambitions of the expressed motivations. Throughout the predecessor modules, emphasis is placed on working collaboratively with fellow students and actively engaging as a part of a team; both for formal assessments and as a routine part of developing a successful approach to learning.

\subsubsection{Persistence and Visibility}

Although the new module will be taught in the second semester of the first year of study, it is essential that the educational resources remain accessible to the students throughout their degree. Its role in professional development also requires that to some extent resources will be available after the students have graduated. The large cohort size and a need for rapid feedback on assessment tasks means that significant effort needs to be addressed to the assessment component of the final system.

\section{DESIGN APPROACHES}

The overarching objective for the design team is to make effective use of information technologies blended with face-to-face activities to support these broad educational, organisational and administrative aims. 
Building on existing experience the design team is basing their approach on an adapted version of a co-design and co-deployment methodology which has been successfully used in previous projects at the University (Millard et al, 2009).

An interim model of the learning design phase of this activity is being mapped as shown in figure 1 . The design team are:
1) Developing use cases which directly align with the module learning outcomes.

2) Integrating a Learner Context approach adapted from Betty Collis' Learning Footprints (Collis and Moonen, 2011)

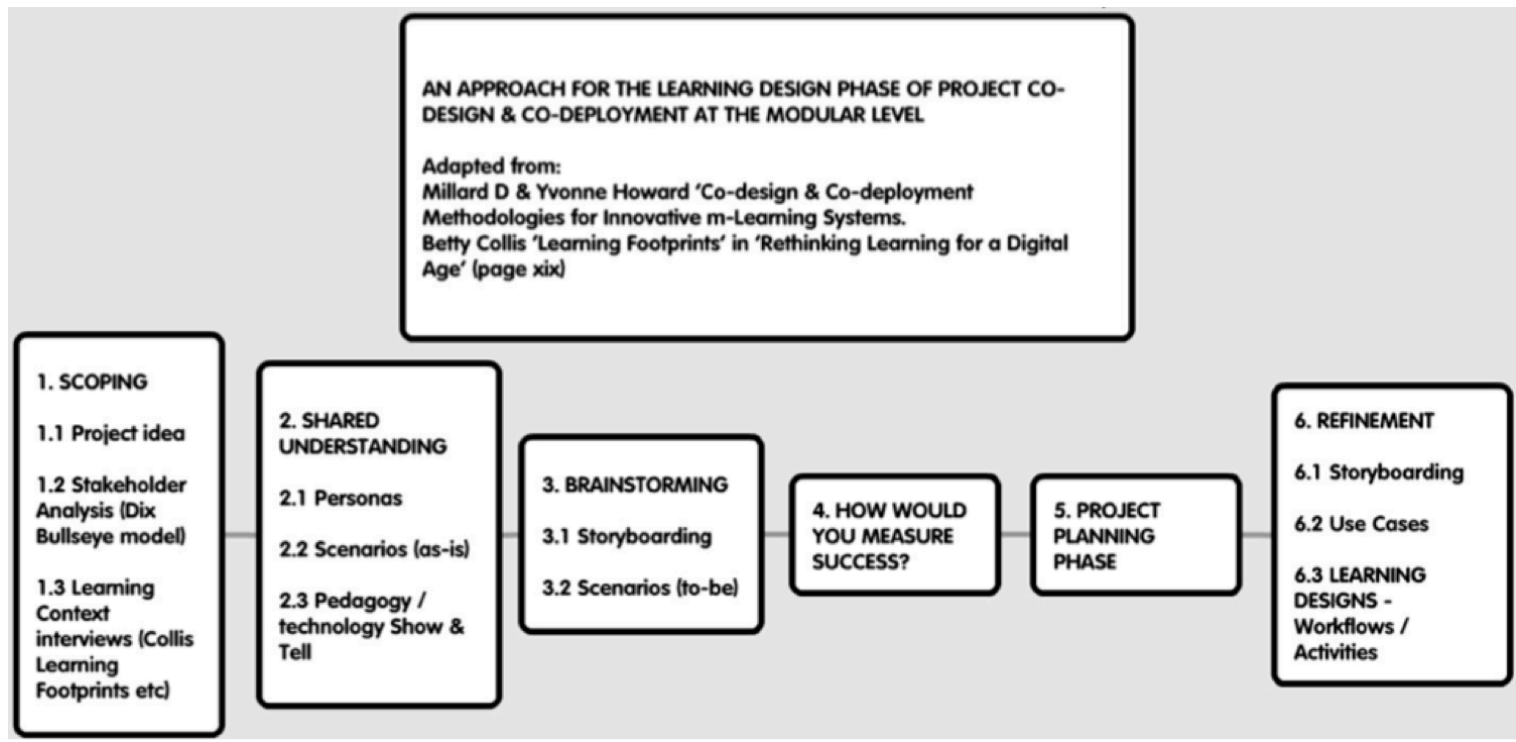

Figure 1: Interim model of learning design phase.

Learner contexts (Figure 2) include: personal characteristics of the learner; cohort cultures; time available to the learner for learning; extrinsic and intrinsic motivations for learning; pedagogical practices of instructors.

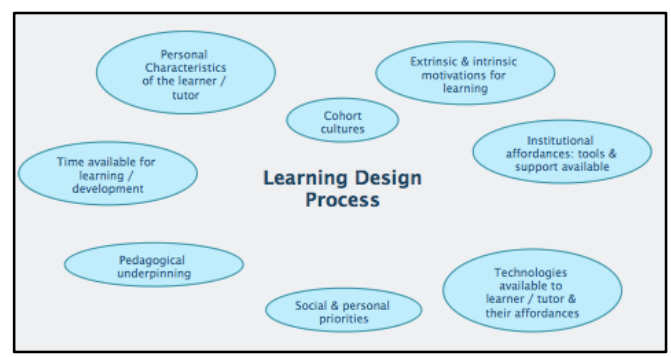

Figure 2: Learner Contexts.

\subsection{Technologies supporting learning}

The design team are keenly aware of the importance of recognising the technology affordances of the tools which are used to realise the design.
The constraints of the existing institutional metalevel technologies is as follows

Commercial products

- Blackboard:

Virtual Learning Environment;

- Turnitin Plagiarism, grading and peer review:

- QuestionMark High Stakes Assessment Engine;

Local tools

- EdShare Open educational repository;

- ECS Notes:

Linked data driven module information pages

- eFolio persistent online Portfolio;

- Mobile Lecture: feedback and learning analytic tool

Whilst readers may be familiar with the functionality of the commercial tools, it may be helpful to provide a little more detail of the local ones. 
Computer Scientists at the University of Southampton have a history of working on hypertext, technology enhanced learning, the web, linked and open data and the semantic web.

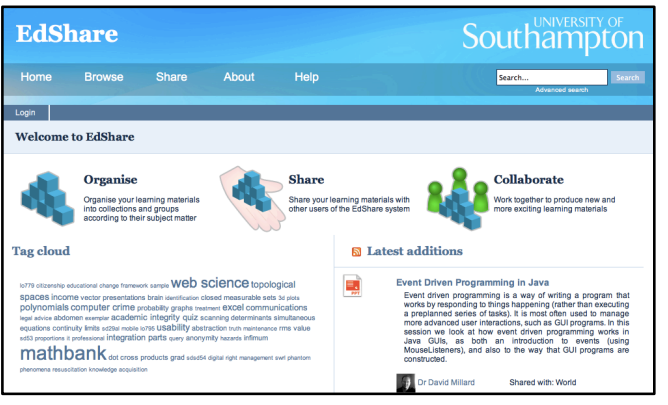

Figure 3: EdShare landing page.

EdShare (the institutional educational repository http:// http://www.edshare.soton.ac.uk Figure 3) and ECS notes (an open data driven information suite see Figures 4 and 5) are both examples of local infrastructure tools which have been developed in association with research projects in these areas.

EdShare is built on the established framework of an EPrints repository. EdShare is the name of the Southampton institutional repository. The design team includes colleagues with a broad experience and understanding of the implementation and user interface factors of establishing repository use (Millard et al, 2009b; Davis et al 2010). Other installations include Humbox and Language Box.

The academics who are working on the module design and specification, already routinely make use of EdShare (Figure 4) to organise and share educational resources.



Figure 4: ECS notes page showing inline resources.

Resources stored in EdShare which are tagged with course codes automatically populate the relevant ECS notes module page. Other open data, for example syllabus information, tutor profiles, student profiles, and handin specification; are automatically aggregated to a single location (Figure 5). Content can also be rapidly edited through wiki's embedded in the module page structure.

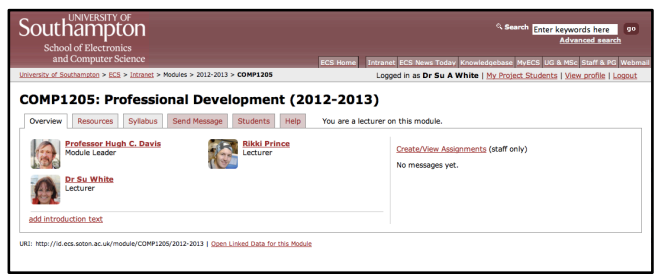

Figure 5: ECS notes page showing linked tutor data.

eFolio (http://www.efolio.soton.ac.uk Figure 6) is a well-tested tool which was originally developed to support psychology students at the university and is also extensively used by undergraduates in medicine and health sciences. A further advantage of this solution is that the resultant portfolio can be accessed or exported after the student has graduated from the university (Furr et al, 2010).

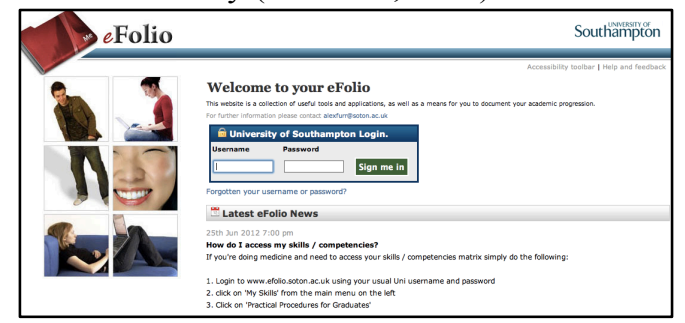

Figure 6: The eFolio front page.

Since this module focuses on professional issues, the affordances of eFolio are being used to promote behaviours aligned with good professional practice from the start of the module e.g.: reflection, digital literacy, online identity and portfolio development. Students will be guided into assembling a portfolio for self-assessment: auditing; evaluating; and critically reflecting upon their strengths and weaknesses in knowledge, skills and understanding within eFolio.

Mobile Lecture (Figure 7) is a rapid feedback tool which has been developed as part of a current research project. It can be used to prompt reflection and self-evaluation of learning at the end of face-toface sessions. It also provides learning analytic information (Aljohani \& Davis, 2012)
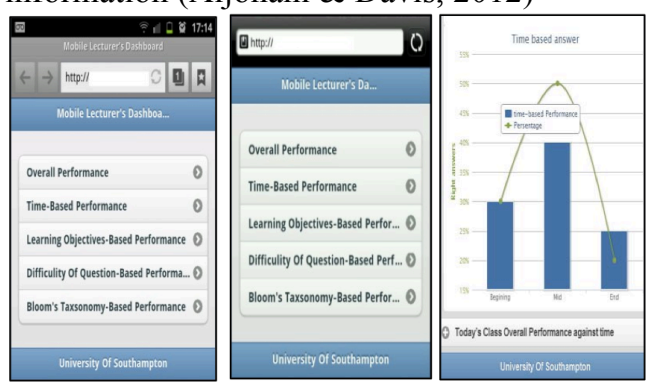

Figure 7: Screenshots from Mobile Lecture's dashboard. 
The university does not currently have any particular specialist tool in use for peer assessment. After extensive evaluation, it was decided to use mix the peer evaluation features of Turnitin for more formal peer evaluation, and WebPA as the tool to support simple developmental peer assessment.

\subsubsection{Design Principles}

As a matter of principle, the design incorporates the use of Open Educational Resources (OERs) where possible. The cost of developing resources from the ground up is expensive, and there is an additional objective of ensuring students become familiar with the value and abundance of OERs.

Holding the idea of identifying and creating reusable design patterns in mind, the affordances of EdShare (Morris et al., 2008; Davis et al., 2010) in conjunction with Blackboard are being utilised. The implementation stores and catalogues discoverable resources (including links to OERs) in EdShare.

Blackboard's role is as a tool to manage the workflow. It organises and prompts progression through study topics, and structured learning activities. The Blackboard workflow management incorporates or links to external tools which introduce purposeful reflection and all types of assessment (diagnostic, self evaluative, formative, integrative and summaries).

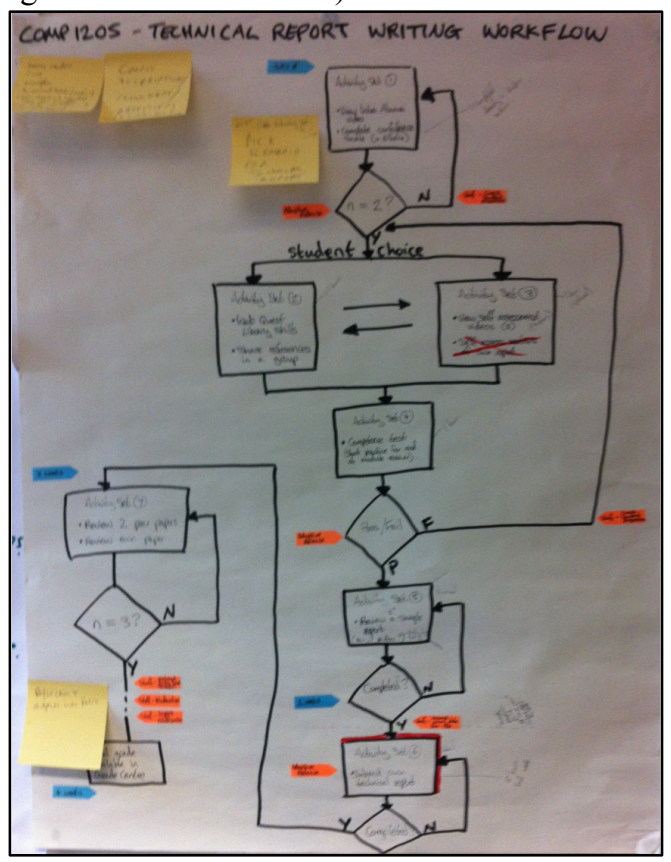

Figure 8: Draft workflow dashboard.

A particular strength of Blackboard and EdShare is that both tools are capable of providing learning analytic information which may be useful in the short and long term. It is intended that such information will be used by the module team and where appropriate be presented to learners to enable them to calibrate their achievements and progress.

QuestionMark and Turnitin are the two remaining commercially available institutional tools. QuestionMark is used as a standalone tool for high stakes assessments. In this module, student achievement will be demonstrated by a mixture of interim courseworks and a final summative examination. Turnitin is routinely used for all submitted courseworks to check the academic integrity of students' work. However its additional affordance is also being used in the context of peer assessment.

\subsubsection{Design Processes}

CITE is perhaps unusual for an institutional centre for educational innovation in that its co-location with an active computer science research group ensures that there is active participation in the design process by researchers who are also highly experienced in software engineering and user design.

The learning design team have experienced a crash course in this particular aspect of computing, and have responded to the challenge.

Whilst the learning curve on heavyweight design tools is significant, pragmatic modifications has enabled the team to capture and communicate their designs in a well structured and ordered manner. The Figures 8 to 11 demonstrate the successive stages in articulating the workflow which follow on from discussions and negotiations with the academic members of the team who will be responsible for the teaching.

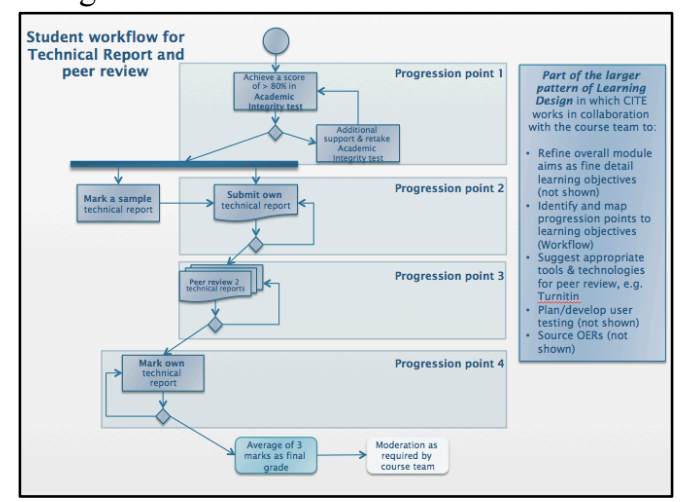

Figure 9: Formalised workflow.

Mock ups and walk through are used to communicate work in progress, and to validate with 
the academics whether the online realisation matches (or even exceeds) their specification.



Figure 9: Workflow explanatory screenshots i.

Since the team is relatively new, although they do have a very wide range of prior experience, some aspects of the workflow implementation are necessarily forcing them to explore new territory. In this respect the ambition to capture design patterns has an additional strength in that it forces the team to examine and articulate implicit understandings and reflect on the replicable and compelling aspects of their experience of the design and its process.

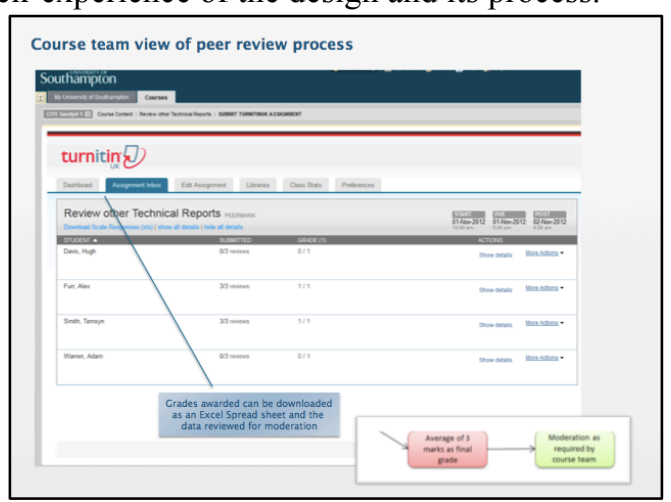

Figure 10: Workflow explanatory screenshots ii.

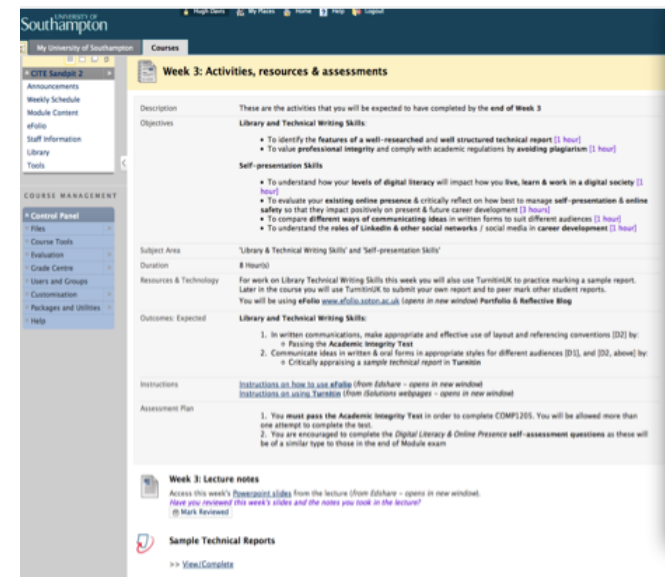

Figure 11: Workflow realisation in Blackboard.

\subsection{Social Computing and Digital Literacies}

One curriculum area which justifies a brief discussion is its own right is that of the integration of social computing and digital literacies

Southampton as a university is particularly aware of the importance and value of the acquisition of digital literacies as a key component of university level education (Figure 12). In this context, digital literacies are the skills needed to live, learn, work, collaborate, influence and lead in the virtual and digital world. With a background of an everdiminishing half-life of information, we are preparing students for jobs that don't yet exist, using work-practices we don't yet know supported by tools not yet invented.

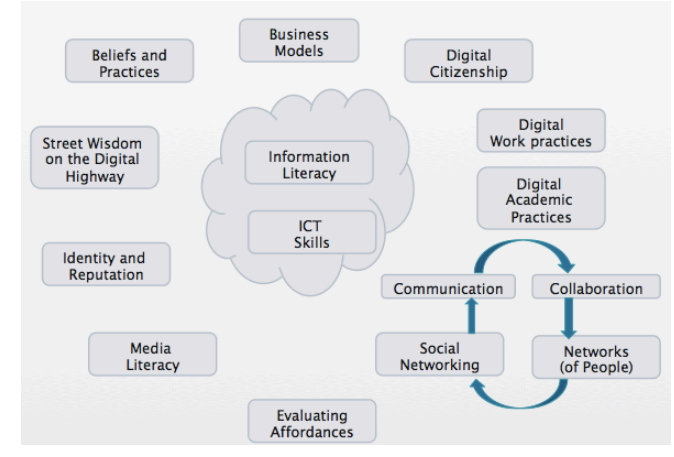

Figure 12: Digital Literacies in the University context.

In the context of the module which we have developed, there is a pressing imperative to 
familiarise students with the use of authentic digital tools and to set them tasks and activities which enable them to acquire a personal and individual understanding of the affordances and limitations of the wide range of social software tools which are in common usage.

For example, having previously required students to create and review CVs we are now asking them to create and evaluate the differences between a traditional $\mathrm{CV}$ and a $\mathrm{CV}$ style profile available via the LinkedIn social networking site.

We are aware that the predominant and preferred tool for our current undergraduates is Facebook, but again we are setting them activities which provide opportunities to understand the technology affordances (and potential personal vulnerability and exploitation) which is afforded by this software, and other similar popular systems.

\section{DISCUSSION}

The endeavour which the design team have undertaken is an ambitious one. The two modules which we are seeking to transpose into a blended format are both already pedagogically complex. Where the design of the existing face-to-face predecessor modules is predominantly constructivist, the realisation of the new blended module is necessarily connectivist (Siemens and Page, 2005).

When considering information technologies supporting learning the area in which we expect to experience the greatest learning is in relation to disciplinary differences and technology affordances. The students will routinely make use of a wide range of information technologies. The blended approach presents web-based learning in a formal and informal context. Students will make use of wiki's and blogs. In ECS, it is unusual to use 'blackboard, even though it is the university's adopted VLE. Our students will be much more familiar with the ECS notes system. We will be closely monitoring usage of both routes into the systems. Further insights need to be gained.

Use is being made of student generated content, and we anticipate a full interim review of the system after its first instantiation. Student interns will be working to analyse the evaluation data and also to provide individual analysis and input for the inevitable tweaking and modifications and redesign. Current experience in ECS suggests that the use of linked and open data is a powerful timesaver which facilitates simple integration of diverse learning materials. The first implementation will provide an opportunity to objectively evaluate the comparative benefits of data driven consolidation with hand-crafted creation.
Reflecting on learning and teaching methodologies and assessment it is believed that the higher level objective of recording, analysing and capturing design patterns will make a valuable contribution to fuelling a more informed discussion of these agendas across the university campus. It is interesting to observe the ways in which the team's working methods have evolved, and to compare them with similar, but different experiences - for example the collaborative creation of educational repositories in modern languages and the humanities.

The blended learning approach has also acted as a vehicle to purposefully design a 'flipped classroom' approach to the teaching. The design pattern and the evaluation of the experience will be valuable.

Using Turnitin for large-scale peer assessments has been implemented in Computer Science elsewhere (Hamer, Ma and Kwong, 2005; Hamer et al, 2011), but is a novel departure for our university. The Southampton implementation is slightly lighter weight than the earlier accounts and it will be interesting to compare the outcomes.

Students continue to exhibit a preference of default social software when left free to establish this social context and learning environment. However it would be possible to view this behaviour as a manifestation of the use of 'worldware' (Morris et al 1994) taken into the twenty-first century. The value of a purposeful requirement to make use of a wide range of authentic social tools, and to reflect on the viability and effectiveness of the methods chosen, remains to be evaluated.

In our local experience, the use of technology enhanced learning in STEM disciplines is not widespread. The model chosen by this initiative is to use technology as a workflow manager in conjunction with authentic tools and authentic tasks. It remains to be this experience is undermined by the acknowledged dissonance between the natural methods of predominantly hard applied fields of study compared to those which best match soft applied disciplines. One thing is sure, this particular design, and its design patterns may give us some insight. One thing which remains unanswered is whether the students will actually enjoy the experience.

\section{CONCLUSIONS}

The task of redesigning any area of the curriculum, whatever the discipline, is not one to be taken lightly. This paper has provided a case study of such an activity, where a specific objective of the team 
engaged in the redesign was to identify the pedagogic and learning design patterns inherent in blended learning.

The potential benefits of such activities are manifold. Perhaps most importantly the systematic acquisition and cataloguing of institutional/organisational knowledge is an activity which every university must surely value. Such knowledge can be of use to achieve diverse objectives; financial stringency, maximal student satisfaction or optimal use of all available resources are identified objectives. This exercise has, this far, yielded some valuable insights.

\section{Information technologies supporting learning;}

There is a strong case for arguing that information technologies can be used to remove the barriers to learning. Providing access to information at anytime and anyplace makes a compelling argument.

From the academic's viewpoint, systems which manage workflow alleviate a major pressure point in the day-to-day working life at university.

It remains to be seen whether learning analytical information is as valuable to educationalists as customer profiles and analytics are to commercial organisations. It seems reasonable to assume that students might benefit from learning about successful practices (students who have a first class mark so far are looking at these web pages...)

Learning and teaching methodologies and assessment;

University teaching has sometimes been described as the last cottage industry. Institutions like the UK's Open University have long established practices of working with a mixed team formally planning and creating learning resources to be integrated with specific educational experiences. Such an approach has provided a framework for much more clearly identifying and utilising preferred learning and teaching methodologies.

The systematic approach to learning design, has provided an opportunity to methodically make use of a wide range of approaches to assessment; a far wider range than might typically be found in a conventional face to face educational programme.

\section{Social context and learning environments;}

Students in the department were already making extensive independent use of technology for social learning activities. It remains to be seen if this structured approach will be acceptable, or be judged a poor second to the ad hoc solutions crafted from the preferred social network chosen and used by the vast majority.
Technology enhanced learning in STEM disciplines.

At the university department being studied, there is a strong infrastructure of linked data driven module pages, many coursework submissions are electronic, and some examinations and tests take place online. Much information is published online, and some academics make wide use of the institutional repository. None the less, it is possible to argue that before this particular exercise technology enhanced learning has not not widely used.

The predominant philosophy here is that technology is good for admin, but teaching and learning is a process where people and face-to-face interactions are prime. This detailed design activity is providing an opportunity to open up from that view, but it will only be more widely accepted if the student learning experience is at least as good, if not better than that afforded by conventional approaches.

There remains, of course, much future work which can be done. When the module is run it will provide a large volume of detailed evaluation data mapping student experience. Alongside routine and systematic evaluations which can be compared to previous years' and previous methods a range of different evaluation approaches are proposed.

Focus group discussions will be used to identify key strengths and weaknesses. These will be complemented by critical and reflective evaluation by academics at the end of the module. It is also intended to recruit students from the cohort to become participative evaluators and co-designers to help identify and create the inevitable and necessary revisions which will emerge.

Equally important, the learning designers will consolidate their knowledge, understanding and reflection of the process. Initial drafts of the formal design patterns will be circulated and subjected to peer review, and the whole pattern of integrative innovation will begin again.

\section{REFERENCES}

Aljohani, N.R. \& Davis, H.C., 2012. Significance of Learning Analytics in Enhancing the Mobile and Pervasive Learning Environments. In Next Generation Mobile Applications, Services and Technologies (NGMAST), 2012 6th International Conference on. pp. 70-74. Available at: http://eprints.soton.ac.uk/343015/.

Biglan, A., 1973a. Relationships between subject matter characteristics and the structure and output of university departments. Journal of Applied Psychology, 57(3), pp.204-213. 
Biglan, A., 1973b. The characteristics of subject matter in different academic areas. Journal of Applied Psychology, 57(3), pp.195-203.

Boud, D. \& Falchikov, N., 2006. Aligning assessment with long-term learning. Assessment \& Evaluation in Higher Education, 31(4), pp.399-413. Available at: http://www.tandfonline.com/doi/abs/10.1080/0260293 0600679050 .

Collis, B. \& Moonen, J., 2012. Foreword. In R. Sharpe, H. Beetham, \& S. De Freitas, eds. Rethinking Learning for a Digital Age. London: Routledge, p. xvii - xx.

Davis, H.C. et al., 2010. Bootstrapping a Culture of Sharing to Facilitate Open Educational Resources. IEEE Transactions on Learning Technologies, 3(2), pp.96-109. Available at: http://eprints.ecs.soton.ac.uk/17386/.

Carr, L.A., Davis, H C \& White, S.A., 2005. AnnAnn A Tool To Scaffold Learning About Programs. In The 6th Higher Education Academy Conference on Infromation and Computer Science. Available at: http://eprints.soton.ac.uk/264296/.

Davis, H C, Carr, L.A. \& White, S.A., 2004. Conducting Examinations On-line. In The 11th International Conference ALT-C. Available at: http://eprints.soton.ac.uk/259678/.

Davis, Hugh C \& White, Su, 2005. A research-led curriculum in multimedia: learning about convergence. In 10th annual SIGCSE conference on Innovation and technology in computer science education . Lisbon, Portugal, pp. 29-33.

Furr, A. et al., 2010. eFolio: a DIY ePortfolio. In L. Creanor et al., eds. ALT-C 2010 - Conference Proceedings. Nottingham: Association for Learning Technology.

Goodyear, P. 2005, 'Educational design and networked learning: Patterns, pattern languages and design practice', Australasian Journal of Educational Technology 21 (1), 82-101

Goodyear, P. \& Retalis, S., ed. (2010), TechnologyEnhanced Learning: Design Patterns and Pattern Languages, Sense, Rotterdam

Hamer, J., Ma, K.T.K. \& Kwong, H.H.F., 2005. A Method of Automatic Grade Calibration in Peer Assessment. In A. Young \& D. Tolhurst, eds. Seventh Australasian Computing Education Conference (ACE2005). Newcastle, Australia: ACS, pp. 67-72.

Hamer, J. et al., 2011. Tools for "contributing student learning". ACM Inroads, 2(2), p.78. Available at: http://dl.acm.org/citation.cfm?doid=1963533.1963553.

Jones, C., Zenios, M. \& Griffiths, J., 2004. Academic use of digital resources: disciplinary differences and the issue of progression. In Networked Learning. Available at: http://www.networkedlearningconference.org.uk/past/n lc2004/proceedings/symposia/symposium $9 /$ jones_et_al $. h t m)$.

Millard, D. et al., 2009a. Co-design and Co-deployment Methodologies for Innovative m-Learning Systems. In Multiplatform E-Learning Systems and Technologies: Mobile Devices for Ubiquitous ICT-Based Education. Available at: http://eprints.soton.ac.uk/267555/.

Millard, D.E. et al., 2009b. The Language Box: Reimagining Teaching and Learning Repositories. 2009 Ninth IEEE International Conference on Advanced Learning Technologies, pp.619-623. Available at: $\mathrm{http}$ ://ieeexplore.ieee.org/lpdocs/epic03/wrapper.htm? arnumber $=5194319$.

Morris, D. et al., 2008. EdShare: towards sharing resources for learning and teaching at the University of Southampton. In Third International Conference on Open Repositories 2008. Available at: http://eprints.soton.ac.uk/265381/.

Morris, P., Ehrmann, S. C., Goldsmith, R., Howat, K. \& Kumar, V. 1994. Valuable, viable software in education: cases and analysis, New York, McGrawHill (Primis).

Siemens, G. \& Page, H., 2005. Connectivism : A Learning Theory for the Digital Age. International Journal of Instructional Technology and Distance Learning, 2(1), pp.1-9. Available at: http://www.itdl.org/Journal/Jan_05/article01.htm.

White, S \& Carr, L.A., 2005. Brave New World: Can We Engineer a Better Start for Freshers? . 35th Annual ASEE/IEEE Frontiers in Education Pedagogies and Technologies for the Emerging Global Economy, pp.26-31.

White, S. \& Liccardi, I., 2006. Harnessing Insight into Disciplinary Differences to Refine e-learning Design. In Frontiers in Education Conference, 36th Annual. pp. $5-10$.

White, S. \& Irons, A., 2007. The research teaching nexus in the computing disciplines: a comparative survey. Informatics Education Europe II: On The State Of Informatics Education In Europe.

White, S et al., 2007. TOPS - Collaboration and Competition to Stretch our Most Able Programming Novices. In IEEE Frontiers in Education. Milwaukee: IEEE. Available at: http://fieconference.org/fie2007/papers/1366.pdf.

White, S. \& Davis, H.C., 2011. Making it Rich and Personal: crafting an institutional personal learning environment. International Journal of Virtual and Personal Learning Environments (IJVPLE), 2(4), p.17. Available at: http://eprints.ecs.soton.ac.uk/22030/. 